Persp. Teol. 39 (2007) 11-20

\title{
PROPOSTA E ÍNDOLE DO CURSO DE TEOLOGIA NA FAJE
}

Johan Konings SJ

RESUMO: Apresenta-se o Curso de Teologia da FAJE na sua atual estrutura. No nível de Graduação (Bacharelado), o curso visa a capacitação dos estudantes nas disciplinas teológicas e outras conexas para a investigação, o exercício do magistério e outras tarefas especializadas no campo da Teologia da Igreja Católica. O caráter confessional e auto-implicativo, que o distingue da Ciência da Religião, não se opõe ao diálogo ecumênico, antes é por este suposto.

O currículo baseia-se na convicção de que a práxis vivida pela comunidade da fé em Jesus Cristo desde as suas origens é o acesso à manifestação específica de Deus que constitui o objeto do estudo teológico cristão.

Este ponto de partida é bipolar e articula dois lugares teológicos principais: o Evento Jesus Cristo com sua preparação no povo de Israel e seu desdobramento na vida da Igreja (teologia histórico-sistemática); e a vida da comunidade cristã em meio aos desafios do mundo atual (práxis cristã). Esta dupla dimensão preside ao estudo desde o início, mediante uma descrição do "Fato Cristão", que proporciona a impostação própria do curso.

O conceito que preside ao ensino na pós-graduação (Mestrado e Doutorado) é o mesmo. A primeira área da pós-graduação é a da Teologia da Práxis Cristã (linhas de pesquisa: - Espiritualidade Cristã e Pluralismo Cultural e Religioso; - Tendências Éticas Atuais), a segunda é a da Teologia Sistemática, (linhas: - Fontes Bíblicas da Tradição Cristã; - Interpretação da Tradição Cristã no Horizonte Atual).

PALAVRAS-CHAVE: Fato cristão, teologia católica, ensino teológico, bipolaridade fé-práxis, fontes cristãs.

ABSTRACT: It presents FAJE'S Theological Program in its current configuration. During the first cycle (Bachelor's degree), the program aims to prepare the students to investigate, teach, and work on other activities related to theological disciplines in the field of theology of the Roman Catholic Church. The confessional 
characteristics and its implications differentiate the theology course from Sciences of Religion, but it does not oppose the ecumenical dialogue, it rather presupposes it.

Its program based on the conviction that the praxis lived by the faith community in Jesus Christ from the very beginning is the access to the specific manifestation of God which constitute the object of the Christian theological studies.

This point of departure is bipolar and it takes on the two main theological settings: Jesus Christ event with its preparation with the people of Israel and its continuation in the life of the Church (historical-systematic theology); and Christian community's life in the midst of the current challenges (Christian praxis). This double dimensions guide the studies from the beginning through the description of the "Christian Fact" which provides the program's own development.

The concept that guides the graduation (License and Doctorate) is the same. Graduation's first area is the theology of the Christian Praxis (research areas: Christian Spirituality and Cultural and religious pluralism; - Current Ethical tendencies), the second is Systematic Theology, (areas: - Biblical sources of Christian Tradition; - Interpretation of the Christian tradition in the current horizon).

KEY-WORDS: Christian fact (event), catholic theology, theological teaching, bipolarity faith-praxis, christian Sources.

$\mathrm{O}$ presente artigo intentará uma "leitura sincrônica" do Curso de Teologia do Departamento de Teologia da FAJE, para desvendar a lógica e o método, ao menos implícito, que o guiam.

\section{Graduação (Bacharelado) ${ }^{1}$}

Consideramos em primeiro lugar o nível de Graduação (Bacharelado). Neste nível, o curso visa a formar os estudantes nas disciplinas teológicas, e em outras disciplinas conexas, mediante uma preparação profundamente científica, que os capacite para a investigação na Teologia, o exercício do magistério e outras tarefas especializadas.

O Bacharelado em Teologia tem por objetivo a formação básica teórica na teologia da Igreja Católica. Por esta, entendemos o discurso sistemático, crítico e hermenêutico sobre a fé cristã vivida conforme a práxis da Igreja Católica. Contudo, diante do público confessionalmente diversificado, esse caráter confessional não se opõe a uma visão e atitude ecumênicas. Se é verdade que a diferença faz surgir o sentido e que para aprender outra língua é preciso assimilar bem a própria, cremos que o estudo sistemático da práxis cristã católica contribuirá para o diálogo ecumênico, no sentido de aprofundar o que pertence à "fé comum" e de articular com clareza a possível pluralidade na interpretação teórica e prática.

${ }^{1} \mathrm{O}$ curso de Graduação foi autorizado pela Portaria $\mathrm{n}^{\circ}$ 264, do MEC/SESu, de 19 de junho de 2006, e implementado a partir de 2007. 
Como Teologia cristã (católica), portanto, esta formação se diferencia de outras ciências, especialmente a Ciência da Religião em geral, que não estuda especificamente a fé cristã.

Como formação teórica, ela se diferencia da formação prática para o serviço ministerial na Igreja Católica, embora articulada com este.

Como formação básica, ela se diferencia do estudo teológico-científico especializado que deve acontecer em nível de Mestrado e Doutorado.

O currículo do curso de Teologia baseia-se na convicção de que a práxis vivida pela comunidade da fé em Jesus Cristo desde as suas origens - o "fato cristão" - é o acesso à manifestação específica de Deus que constitui o objeto do estudo teológico cristão.

Este ponto de partida é bipolar e articula duas dimensões ou lugares teológicos principais: por um lado, as fontes históricas da fé cristã, o Evento Jesus Cristo com sua preparação no povo de Israel e seu desdobramento na vida da Igreja (teologia histórico-sistemática); por outro, como resultante, a vida da comunidade cristã , hoje, em meio aos desafios do mundo atual (práxis cristã). Esta dupla dimensão é levada à consciência desde o início do curso, mediante uma descrição do "Fato Cristão", que proporciona a impostação própria do curso.

Evidentemente, o ponto de partida - o fato cristão - está situado no espaço hermenêutico ou de compreensão que é a experiência cristã na América Latina, hoje, com sua explicitação teológica original adquirida nos decênios recentes e com os novos desafios surgidos nestes últimos anos. Além disso, compartilha o espaço pluralista da sociedade contemporânea com outras experiências religiosas, com as quais deve entrar em diálogo.

A partir dessa intuição básica, o currículo se desdobra em grandes linhas segundo a organização clássica do estudo teológico, escolhendo-se em cada semestre uma matéria principal como enfoque central, em redor do qual se agrupam, com certa afinidade, na medida do possível, as outras matérias. Neste currículo, as tradicionais distinções entre teologia positiva e especulativa ou entre teologia sistemática e prática se vêem relativizadas, como fica evidenciado nas considerações que se seguem.

"Da fé para a fé" $(\mathrm{Rm} 1,17)$, assim poder-se-ia resumir a trajetória que pretendemos seguir. Entenda-se, contudo, a fé como práxis, a fé vivida, em todas as suas dimensões, tanto as subjetivas como as objetivas, as teóricas (doutrina) como as práticas (espiritualidade, celebração do Mistério, vida moral inspirada pelo amor de Deus revelado em Cristo, pastoral). Por isso, a trajetória do nosso teologizar poderia resumir-se também neste lema: "Da práxis para a práxis", entendendo-se a práxis não como mera prática externa, mas como interpretação-no-agir de uma intuição ou pré-compreensão de um sentido fundamental indicado pelo Evento Jesus Cristo. 
Propõe-se, portanto, um pensar circular, não porém um círculo fechado, mas sim, uma espiral aberta. Tem continuamente diante dos olhos (1) a práxis fontal que se encontra assinalada nas assim chamadas "fontes da Revelação" e nos lugares teológicos da história atrás de nós, e por outro lado (2) a práxis que continuamente se projeta como afazer - história como tarefa - na assim chamada teologia prática. Entre estes dois pólos, que são duas figuras de uma mesma manifestação de Deus entre nós, desenvolvese o pensamento da Teologia sistemática, procurando verbalizar de modo crítico o significado universal daquilo que Deus fez, faz e fará conosco, em Cristo.

O atual currículo, que, em conformidade com a legislação brasileira, não supõe outros estudos superiores prévios, integra nas etapas iniciais matérias filosóficas e humanísticas consideradas necessárias para a reflexão aprofundada que o programa propõe. Assim, a primeira e a segunda etapas (semestres) correspondem ao preâmbulo filosófico, pré-requisito para um estudo sério da Teologia. Evidentemente, os alunos que já fizeram um curso de Filosofia ou equivalente são dispensados dessas matérias.

A terceira etapa procura ambientar o aluno na Teologia propriamente, descrevendo, por um lado, o fato cristão e a pastoral hoje, e, por outro, apresentando os textos fundamentais da experiência bíblica do Antigo e do Novo Testamento.

$\mathrm{Na}$ quarta e quinta etapas enfoca-se o evento Jesus Cristo na história e no mundo, como também o estudo dos grandes dogmas cristológicos e teológicos que marcaram definitivamente a linguagem da fé cristã trinitária.

Da sexta à oitava etapas, a partir de um estudo mais atento da comunidade cristã, desdobra-se a compreensão da vida humana à luz da identidade cristã, enquanto o aluno vai progressivamente realizando sua síntese pessoal mediante a elaboração de um trabalho científico e a preparação do exame compreensivo final.

\section{$1^{a}$ e $2^{a}$ etapas: Preâmbulo filosófico}

Nos primeiros semestres do programa, antes de entrar no estudo da Teologia propriamente, o aluno é introduzido no mundo do pensamento e da reflexão. O pensar teológico buscará seu contexto no mundo do pensar em geral e será confrontado com a exigência de se apresentar como um pensar rigoroso, metodologicamente articulado, de forma a capacitar-se para $\mathrm{o}$ diálogo com o mundo circundante. $\mathrm{O}$ aluno faz a sua escolha - no mínimo, 30 créditos - a partir do elenco de disciplinas, consideradas importantes para a reflexão teológica e oferecidas no curso de Filosofia do Departamento de Filosofia da FAJE, como, por exemplo: Introdução à Filosofia, Lógica, Teoria do Conhecimento, Filosofia da Natureza, Antropologia Filosófica, Ética, Metafísica, Filosofia da Religião, História da Filosofia etc. 


\section{$3^{a}$ etapa: O Fato Cristão}

No início da terceira etapa administram-se os cursos de Introdução à Teologia e Introdução à Bíblia, para situar os alunos no contexto global da reflexão teológica, apresentando de forma sintética todo o percurso a ser realizado.

A disciplina central é o Fato Cristão, que proporciona uma síntese présistemática da fé-práxis cristã. Esta disciplina deve conscientizar os alunos da necessidade de uma compreensão continuamente renovada da fé em diálogo com o contexto sócio-cultural. A partir da pergunta: "Que faz o cristão?", o pensamento se dirige para outra: "Que faz alguém ser cristão?"

Na Teologia Fundamental, concebida como meta-teologia, apresenta-se a criteriologia da fé e do afazer teológico, descrevendo de modo formal e crítico os conceitos de Fé, Revelação, Inspiração, Tradição etc.

Dirigindo, concomitantemente, o olhar para as fontes, estuda-se a manifestação histórica fundante da revelação cristã, conservada na Lei e nos Profetas do Antigo Testamento (Pentateuco, Livros Históricos, Livros Proféticos) e na narrativa a respeito de Jesus oferecida pelo Evangelho de Marcos.

A disciplina Seminário de Pesquisa e Redação em Teologia introduz os estudantes na arte de produzir textos teológicos com rigor científico.

\section{$4^{a}$ etapa: O Evento Jesus Cristo}

Na quarta etapa focaliza-se especificamente a reflexão sistemática sobre Jesus de Nazaré, o Cristo, e sua presença e significação salvífica, que transcende sua vida terrestre (Cristologia e Soteriologia).

Em torno deste enfoque central, continua-se o estudo do Novo Testamento pelos Escritos Paulinos, que constituem historicamente a primeira expressão do Evento Jesus Cristo, acentuando fortemente sua dimensão soteriológica; e pelo Evangelho de Mateus, destacando-se, sobretudo, o cumprimento das profecias messiânicas ou releitura cristã do Antigo Testamento, o discipulado do Cristo Mestre e a sua comunidade.

Depois de uma introdução geral à Teologia da Liturgia, considera-se a prática sacramental do memorial do Cristo, na Eucaristia, testemunha e fonte de expressão da fé no evento salvífico que tem seu centro na missão e obra de Jesus de Nazaré.

Desdobra-se ainda o enfoque cristocêntrico no estudo dos fundamentos do agir cristão, conjugados com os outros conceitos e critérios fundamentais da teologia moral (Moral Fundamental).

Com a finalidade de personalizar o estudo, é oferecido um Seminário de Leitura, proporcionando aos alunos a leitura acompanhada de um texto fundamental e recente de Teologia e preparando-os para o trabalho teológico pessoal. 


\section{$5^{a}$ etapa: O Deus de Jesus Cristo}

Na quinta etapa, o enfoque central é a reflexão sobre o Deus revelado por Jesus de Nazaré e que se dá a conhecer nele, na sua dimensão suprahistórica: o tratado de Deus-Trindade, com uma síntese dos dogmas cristológico-trinitários dos primeiros Concílios. Os cursos de Teologia Patrística e História da Igreja Antiga (até Calcedônia) vêm completar os estudos cristológico-trinitários.

Este estudo é acompanhado pela parte do Novo Testamento que mais explicitamente expressa a consciência cristã a respeito do Deus de Jesus Cristo, o Evangelho e Cartas de João. Além disso, estudam-se também as outras Cartas Católicas, a Epístola aos Hebreus e o Apocalipse.

Continua-se o estudo dos sacramentos da Iniciação Cristã com o "grande batismo" - Batismo e Crisma -, que, como expressão da fé trinitária, segundo a fórmula batismal, está intimamente ligado ao tratado-chave deste semestre, a Trindade. Aborda-se ainda o sacramento da Ordem, no quadro de uma visão geral da vivência sacramental.

Na Teologia Moral está programada a Moral da Pessoa, evitando-se, porém, o conceito da pessoa-centro que prevalece na primeira e na segunda Modernidade, para descrever a pessoa como pólo numa estrutura de alteridade: daí a concentração na Ética da Sexualidade.

As disciplinas históricas continuam na História da Igreja Medieval.

\section{$6^{a}$ etapa: A Comunidade da fé em Jesus Cristo}

Na sexta etapa, o enfoque central é a Eclesiologia, com seus desdobramentos na vida da Igreja. Próximo da temática eclesiológica está o estudo do Direito Canônico Fundamental. A Introdução à Teologia Pastoral continua a temática apresentada no Fato Cristão, agora sob o aspecto da sua vivência eclesial.

Os estudos bíblicos continuam pela Literatura Sapiencial, no Antigo Testamento, e pelos Escritos Lucanos (Evangelho e Atos), no Novo, os quais constituem um excelente referencial bíblico para o enfoque eclesiológico.

No âmbito da sacramentologia estudam-se os sacramentos da Unção dos Enfermos e da Penitência, relacionados com o tratado de Eclesiologia sob o viés da "Igreja santa e pecadora" e da dimensão eclesial do perdão.

\section{$7^{a}$ etapa: O Homem Novo em Cristo}

A matéria principal da sétima etapa é a Antropologia Teológica, que descreve o significado da salvação e da graça em Cristo na existência do ser humano como indivíduo e como comunidade, no contexto da Criação e da Redenção, de modo especial pela graça de Deus manifestada e outorgada em Cristo. Este curso articula-se evidentemente em continuidade com os 
elementos cristológicos e soteriológicos estudados anteriormente. Especial atenção será dada à realização da existência cristã no mundo de hoje, diante dos desafios atuais. No contexto da antropologia, e levando em consideração a religiosidade popular, insere-se o estudo da Mariologia, retomando evidentemente suas referências cristológicas e eclesiológicas.

Nesta etapa, o agir cristão é estudado na Moral Social e no curso de Bioética. Além disso, faz-se uma abordagem do Matrimônio, sob vários aspectos: sacramental, antropológico e moral, em consonância com o estudo do Direito Canônico Sacramental, que privilegia as questões matrimoniais. Estudamse também a teologia dos Salmos e alguns Temas Especiais de Liturgia.

O estudo da história eclesiástica continua a História da Igreja Moderna e Contemporânea, incluindo um enfoque especial sobre a América Latina.

\section{$8^{a}$ etapa: Deus, tudo em todos}

A oitava etapa completa a anterior, enfocando a perspectiva salvífica final. Estuda-se a Escatologia, na realidade uma continuação da Antropologia Teológica, abordada anteriormente. Inclui-se também a Teologia da Espiritualidade, na qual se realçam tanto o revelação de Deus quanto as categorias antropológicas de sua acolhida.

O restante desta última etapa é dedicado à conclusão da Monografia de Bacharelado e à preparação do Exame Compreensivo Oral por meio do Seminário de Síntese Teológica, no qual se recapitula a teologia sistemática, com suas implicações bíblicas e históricas, em articulação com os desdobramentos na práxis cristã. Por ocasião deste estudo completa-se a percepção da hermenêutica teológica fundamental, ou meta-teologia, que já tinha sido apontada na disciplina de Teologia Fundamental.

\section{Matérias optativas}

Ao longo do curso, o aluno deverá inscrever-se em, no mínimo, três matérias optativas, em torno de temáticas escolhidas em diversos campos e considerando os novos acentos teológicos. Isto lhe propiciará o enriquecimento de seu universo teológico global e o aprofundamento dos temas de seu interesse. (Quem se prepara para o ministério ordenado, deverá, obrigatoriamente, inscrever-se em Direito Canônico Sacramental.)

\section{Acompanhamento de Estudos}

O Acompanhamento de Estudos tem uma importância especial e é uma característica do curso. Desde o primeiro semestre, cada aluno ordinário é confiado a um professor do quadro permanente, que o acompanhará ao longo de todo o curso. O Acompanhamento de Estudos é uma instância 
privilegiada de diálogo e de discernimento da vida acadêmica do estudante, e deve facilitar a compreensão do estudo teológico como uma contínua leitura hermenêutica das fontes e da práxis histórica da fé cristã.

\section{Pós-Graduação (Mestrado e Doutorado) ${ }^{2}$}

No nível de Pós-Graduação, o enfoque continua, como na Graduação, o da Teologia cristã e da formação teórica, porém de modo aprofundado. Mais especificamente pode-se dizer que no Mestrado se visa à aquisição de uma metodologia de pesquisa e redação avançada, comprovando a capacidade de lecionar a Teologia num campo específico, enquanto no Doutorado o acento é posto na abordagem original e abrangente do tema escolhido para a tese. Se, no Mestrado, se visa em primeiro lugar ao aperfeiçoamento pessoal do estudioso, no Doutorado importa antes de tudo a genuína e confiável contribuição para a Ciência Teológica.

O conceito da Teologia cristã que preside ao ensino na Pós-Graduação é fundamentalmente o mesmo que na Graduação. As duas referências são as fontes da fé e a práxis cristã. Daí as duas áreas de nosso curso de PósGraduação. A primeira é a da Teologia da Práxis Cristã, com duas linhas de pesquisa: - Espíritualidade Cristã e Pluralismo Cultural e Religioso; Tendências Éticas Atuais. A outra área é a da Teologia Sistemática, que igualmente inclui duas linhas: - Fontes Bíblicas da Tradição Cristã - Interpretação da Tradição Cristã no Horizonte Atual. Neste quadro são apresentados atualmente nada menos que trinta e seis projetos, nos quais os alunos podem enquadrar seus trabalhos de pesquisa.

\section{Reflexão}

A visão de conjunto que acabamos de esboçar revela o conceito que subjaz ao modo de fazer Teologia em nossa Faculdade: a "leitura" da práxis cristã, na Tradição e na atualidade, em interação com o contexto histórico, como lugar da revelação do Deus de Jesus Cristo.

Este olhar sobre a práxis cristã não se limita à prática católica, como ilustra o considerável número de não-católicos tanto no corpo discente como no docente. Por outro lado, embora aberta a alunos de todos os credos, como é exigido para o reconhecimento pelo MEC, o Departamento de Teologia da FAJE não desiste de seu caráter confessional. Oferece, inclusive, o diploma da Faculdade Canônica de Teologia (Católica), nos níveis de Bacharelado,

${ }^{2}$ O Mestrado foi recomendado pela CAPES desde 1997 (portaria $\mathrm{n}^{\circ} 1432$, do MEC/ CAPES, de 2 de fevereiro de 1999); o Doutorado desde 2002. 
Mestrado (Licenciatura) e Doutorado, de acordo com as normas da "Sapientia Christiana", para aqueles que assim desejam, principalmente os que se preparam para a docência ou o trabalho teológico em instituições católicas ${ }^{3}$.

A perspectiva ao mesmo tempo católica e ecumênica leva a um aprofundamento do sentido do afazer teológico. Se na Graduação, comprometida com a formação de ministros católicos, o ensino do dogma católico é parte integrante do programa, no nível de Pós-Graduação procura-se qualificar o aluno no método teológico para exercê-lo com competência e coerência dentro de seu próprio credo. Mas isso não significa uma indefinição aberta a qualquer jeito de fazer teologia. Dentro de uma racionalidade universal, válida para todo o pensamento humano, o método reflete as prioridades da compreensão própria da fé. A tradição católica nunca deixará de incluir no seu método teológico - sem renúncia à razão - a consideração da Tradição e do Magistério (entendido como "ministério"), que orienta sua compreensão e interpretação na prática. Ora, isso sensibiliza também os alunos não católicos para o fato de que a S. Escritura é um momento da Tradição. Por outro lado, a convivência com o lema da "sola Scriptura", professado pelos oriundos da Reforma Protestante, obriga o teólogo católico, tanto o discente como o docente, a considerar que na tradição da fé não pode crescer nenhuma semente que não deite suas raízes na tradição fundante consignada nas Escrituras.

Sob um outro viés, as formas de "interpretação na prática" que, juntamente com as fontes, servem de referência para a reflexão teológica, não são qualquer uma, nem mesmo dentro do âmbito católico. Acreditando que o universal revela seu significado no concreto, orientamos nosso olhar para as manifestações da práxis cristã que se apresentam à compreensão préreflexiva do "fato cristão" como representativas de seu sentido fundamental. Daí a importância da disciplina do Fato Cristão no início do estudo. Nesta percepção inicial priorizamos experiências cristãs de diversos momentos, tanto do tempo das "fontes" como de todas as épocas da comunidade cristã e também do momento atual, que refletem o espírito de Jesus Cristo percebido na tradição das fontes cristãs. Poderíamos dizer que aplicamos ao conjunto do "fato cristão" o que Lutero disse a respeito da interpretação bíblica, no caso do Antigo Testamento: procurar "o que gera Cristo" ("was Christum treibt").

Pode-se objetar que isso é um método circular. Respondemos que exatamente o pensamento do último século, a fenomenologia, de Husserl a Ricoeur e Levinas, pensadores próximos do mundo bíblico, nos fornece um organon coerente para refletir num círculo que não seja vicioso, mas se articule como abertura constante para um excedente de sentido. Claro que

${ }^{3}$ As outras instituições no Brasil que oferecem essa qualificação são a Faculdade Nossa Senhora da Assunção em São Paulo e a Faculdade de Teologia da PUC do Rio de Janeiro. 
não todos os que "fazem teologia" em nosso meio explicitam essa consideração metodológica fundamental. Muito do trabalho pode ser feito num nível mais descritivo, tanto na observação da práxis como na exegese das fontes. Mas a consciência metodológica que acabamos de evocar é importante para compreender o caráter de "discurso segundo da Revelação" que é o da Teologia cristã. Ela não parte de uma tabula rasa, mas de uma percepção pré-reflexiva do que podemos chamar o "espírito" daquilo que reconhecemos nas fontes e nos momentos fundantes.

Dito isso, não é difícil compreender que algumas realizações no âmbito cristão suscitam nossa preferência como foco de reflexão, outras menos, ou de outro modo. Um Jesus nos moldes midiáticos consumistas e sensacionalistas pode até suscitar uma suspeita incentivadora de análise crítica, mas não leva a desfrutar uma fecunda ampliação de sentido - ao contrário do Jesus das comunidades sofridas da nossa Ameríndia e Caribe. Ou, num outro nível, dificilmente se prestará a um afazer teológico, no sentido que descrevemos, uma compreensão doutrinária que, com o pretexto de absoluta fidelidade, não permite nenhuma interpretação a não ser aquela que ela mesma, consciente ou inconscientemente, veicula.

A reflexão teológica é um diálogo entre a fides quaerens intellectum e a ratio fide illustrata ${ }^{4}$, entre a fé como experiência e tradição e a razão como busca de sentido, diálogo sem fim, mas não sem sentido. Nele queremos engajar os afazeres acadêmicos de nossa Faculdade.

Johan M. H. J. Konings SJ, Doutor em Teologia e Mestre em Filosofia e em Filologia Bíblica pela Universidade Católica de Leuven (Lovaina), Bélgica, é professor de exegese bíblica na FAJE em Belo Horizonte-MG. Entre outras obras publicou: Descobrir a Bíblia a partir da Liturgia (São Paulo: Loyola 1997); A Palavra se fez livro (2a ed. São Paulo: Loyola, 2002); Liturgia Dominical: Mistério de Cristo e formação dos fiéis: anos A - BC (2 $2^{\text {a }}$ ed. Petrópolis: Vozes, 2003); Ser cristão (3a ed., Petrópolis: Vozes, 2004); Evangelho segundo João: amor e fidelidade ( $2^{\mathrm{a}}$ ed., São Paulo: Loyola, 2005); A Bíblia nas suas origens e hoje ( $6^{a}$ ed. Petrópolis: Vozes, 2006). É responsável pela coordenação da Bíblia: Tradução Ecumênica (São Paulo: Loyola, 1994), da Bíblia Sagrada: Tradução da CNBB $\left(* 5^{\text {a }}\right.$ ed. Brasília: CNBB, 2007), e da tradução brasileira de H. DENZINGER / P. HÜNERMANN, Compêndio dos símbolos, definições e declarações de fé e moral (*São Paulo: Loyola, Paulinas, 2007). [*= para sair]

Endereço: Av. Dr. Cristiano Guimarães, 2127 - Bairro Planalto

31720-300 Belo Horizonte - MG

e-mail: konings@faculdadejesuita.edu.br

${ }^{4}$ Cf. CONC. VAT. I, Const. dogm. Dei Filius, cap. 4: DH 3016. 